\title{
Antibody-secreting implant reduces AD pathology in mice
}

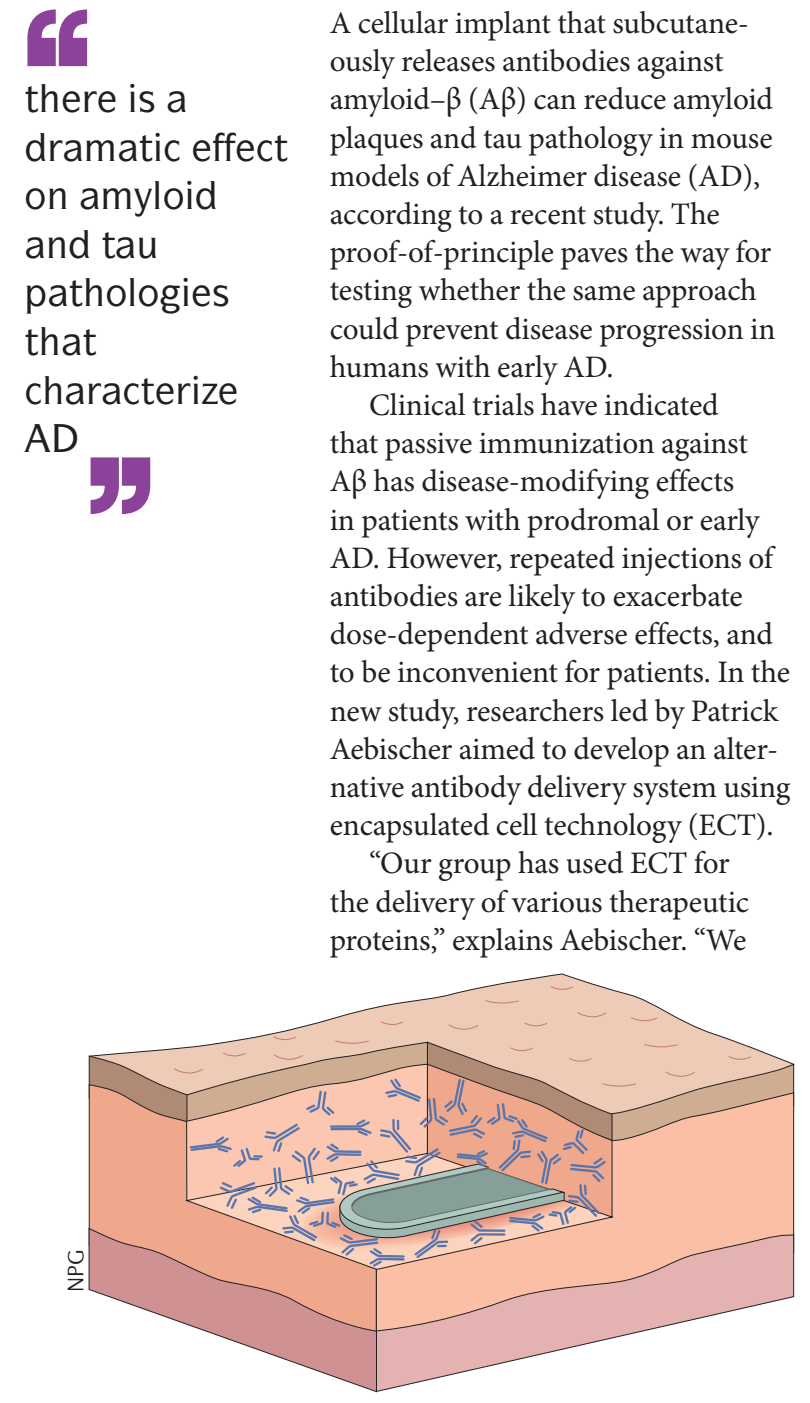

recently developed a high-capacity

cell encapsulation device for subcutaneous implantation and optimized the genetic engineering of myoblast cells for high-rate antibody secretion. We have now adapted this technology to systematically administer recombinant anti-A $\beta$ antibodies."

The team genetically engineered C2C12 mouse myoblasts to secrete a recombinant antibody, called mAb-11, against $A \beta$ and amyloid plaques. The myoblasts were placed inside the encapsulation device, a polypropylene membranous structure with pores that allow release of the secreted antibodies. The researchers then implanted the devices subcutaneously into two mouse models of $\mathrm{AD}$ : 5FXAD mice, which exhibit amyloid plaques by 2 months of age, and TauPS2APP mice, which slowly develop amyloid and tau pathology. Control mice of both strains were implanted with cells that expressed only GFP.

In both mouse models, the cellular implant led to steady plasma levels of mAb-11 for approximately 9 months. The antibodies entered the brain, and their binding to $A \beta$ and amyloid plaques suppressed the progression of amyloid pathology. In 5XFAD mice, implantation after plaque onset led to a reduced density of plaques in the cortex, hippocampus and thalamus at 6 months of age. Similarly, in TauPS2APP mice, implantation at 6 months before the onset of amyloid deposition reduced amyloid pathology throughout the cortex and hippocampus at 1 year of age. Reduction in $A \beta$ deposition was also accompanied by a reduction in tau pathology in the CA1 region of the hippocampus.

"These results show that peripheral passive immunization against $A \beta$ is effective," says Aebischer. "When ECT is used for continuous antibody administration before the onset of amyloid plaque deposition, there is a dramatic effect on amyloid and tau pathologies that characterize AD."

Aebischer and his team now hope to translate the technique into humans. "We are currently developing a human cell line compatible with our ECT platform. This approach has clear translational potential not only for $\mathrm{AD}$, but also for an increasing number of neurological conditions that can be treated with recombinant antibodies," he concludes.

Ian Fyfe

ORIGINAL ARTICLE Lathuilière, A. et al. A subcutaneous cellular implant for passive immunization against amyloid $-\beta$ reduces brain amyloid and tau pathologies. Brain http:// dx.doi.org/10.1093/brain/aww036 (2016). 